E3S Web of Conferences 1, 07006 (2013)

DOI: $10.1051 / \mathrm{e} 3$ sconf/20130107006

(c) Owned by the authors, published by EDP Sciences, 2013

\title{
An uncertainty estimate of global mercury emissions using the Monte Carlo technique
}

\author{
S. Cinnirella, ${ }^{1}$ and N. Pirrone ${ }^{2}$ \\ ${ }^{1}$ CNR-Institute of Atmospheric Pollution Research, Division of Rende, Rende, Italy, s.cinnirella@iia.cnr.it \\ ${ }^{2}$ CNR-Institute of Atmospheric Pollution Research, Monterotondo Scalo, Italy
}

\begin{abstract}
In recent years, a substantial amount of work has been done to evaluate uncertainty associated with major industrial source emissions. Yet, little has been done to assess uncertainty associated with natural source emissions. Importantly, uncertainty estimates continue to be particularly relevant in the assessment of potential regulatory options, as confidence in emissions can lead to different cost-benefit assessments. To address this problem, we employed the Monte Carlo technique to improve uncertainty estimates associated with mercury emissions from both natural and anthropogenic sources. Results demonstrate that uncertainties, as they are understood in the existing literature, are overestimated. While we are aware that a probabilistic approach like the Monte Carlo technique has certain limitations (it does not consider the accuracy of available input data, for example) it still is useful in crafting a better assessment of mercury emission uncertainty.
\end{abstract}

Key words: Uncertainty, stochastic simulation, error natural sources, anthropogenic sources

\section{Introduction}

Over the last few years, a number of newly published papers have provided revised global assessments of mercury emissions from both anthropogenic (Pacyna et al., 2010; Pirrone et al., 2010) and natural sources (Friedli et al., 2009a; Friedli et al., 2009b; Pacyna et al., 2010; Streets et al., 2009a).

These global assessments have improved information on mercury emissions from both anthropogenic sources and natural sources, provided new global and regional assessments of atmospheric mercury transport and deposition patterns, highlighted major issues related to the definition of source-receptor relationships, and provided new scenarios of future mercury emissions (AMAP/UNEP, 2008; Pirrone et al., 2009; Streets et al., 2009b; Pacyna et al., 2010; Pirrone et al.,2010).

In addition, a substantial amount of past work has been done to evaluate the uncertainty associated with major industrial sources (Lindberg et al., 2007; Pacyna et al., 2003; Streets et al., 2005; Swain et al., 2007; Wu et al., 2009; Wu et al., 2006), while little was done to assess the uncertainty associated with natural source emissions. Although estimates of current anthropogenic emissions for many other pollutants are often cited with a greater precision, a general uncertainty of $\pm 30 \%$ for major industrial sources of mercury is widely accepted.

Uncertainties are particularly relevant in the assessment of potential regulatory options, as confidence in emissions numbers can lead to different cost-benefit assessments and, therefore, drive environmental policies at national and international levels.

To improve the uncertainty estimates associated with mercury emissions from both natural and anthropogenic sources, the Monte Carlo technique has been adopted.

\section{Materials and Methods}

The Monte Carlo technique is a practical way to evaluate uncertainty.By employing a stochastic simulation technique, the Monte Carlo technique bases its estimate on the generation of random values from specified density functions (Buslenko et al., 1966; Hammersley and Handscomb, 1979). The simulation randomly generates thousands of iterations of data,to account for the uncertainty and performance variation associated with a particular variable.

In our case, we generated anuncertainty estimate 
Table 1. Upper and lower bounds of mercury emissions $(\mathrm{Mg} / \mathrm{yr})$ based on several published papers and international reports.

\begin{tabular}{|c|c|c|c|c|c|c|c|}
\hline Natural & Avg & Min & Max & Anthropogenic & Avg & Min & Max \\
\hline Atlantic Ocean & 840 & 220 & 1680 & Coal \& oil combustion & 845 & 810 & 880.1 \\
\hline Pacific and Indian Ocean & 1700 & 520 & 3400 & Non-ferrous metal production & 226 & 141.4 & 310.02 \\
\hline Antarctic Ocean & 12 & 4 & 22 & Pig iron and steel production & 44 & 43.2 & 45.3 \\
\hline Mediterranean & 70 & 8 & 80 & Cement production & 213 & 189.3 & 235.7 \\
\hline Coastal waters & 60 & 30 & 100 & Caustic soda production & 105 & 46.8 & 162.9 \\
\hline Lakes & 96 & 57,7 & 194 & Mercury production & 29 & 8.84 & 50 \\
\hline Forest & 342 & 103 & 425 & Gold production & 256 & 111.3 & 400.02 \\
\hline Tundra/Grassland/Savannah/Prairie/Chaparral & 448 & 248,8 & 895 & Waste disposal & 111 & 35 & 187 \\
\hline Desert/Metalliferrous/ Non-vegetated Zones & 546 & 302 & 1353 & Coal bed fires & 32 & 16 & 48 \\
\hline Agricultural areas & 128 & 68 & 258 & VCM & 24 & 12 & 36 \\
\hline Evasion after MDE & 200 & 100 & 300 & Other & 45 & 25.54 & 65 \\
\hline Volcanoes/Geothermal & 90 & 60 & 600 & Gasoline, diesel, kerosene & 0.19 & 0.378 & 0.57 \\
\hline Biomass burning & 675 & 435 & 915 & & & & \\
\hline Total & 5206 & 2157 & 10222 & & 1930 & 1440 & 2421 \\
\hline
\end{tabular}

Table 2. Key outputs of the Monte Carlo simulation

\begin{tabular}{|c|c|c|c|c|c|c|c|c|}
\hline \multirow[b]{2}{*}{ Error (\%) } & \multicolumn{4}{|c|}{ Natural sources } & \multicolumn{4}{|c|}{ Anthropogenic sources } \\
\hline & 5 & 10 & 20 & 30 & 5 & 10 & 20 & 30 \\
\hline Iterations (\#) & 1019 & 255 & 64 & 28 & 155 & 39 & 10 & 4 \\
\hline Average (Mg/yr) & 6165 & 6204 & 6162 & 6126 & 1935 & 1935 & 1925 & 1873 \\
\hline Median (Mg/yr) & 6148 & 6130 & 5957 & 5899 & 1937 & 1929 & 1924 & 1924 \\
\hline Standard deviation $(\mathbf{M g} / \mathbf{y r})$ & 1029 & 1038 & 1062 & 1132 & 111 & 117 & 99 & 91 \\
\hline True error (Mg/yr) & 96.67 & 195.07 & 399.14 & 638.47 & 26.64 & 56.24 & 95.18 & 131.90 \\
\hline
\end{tabular}

a)

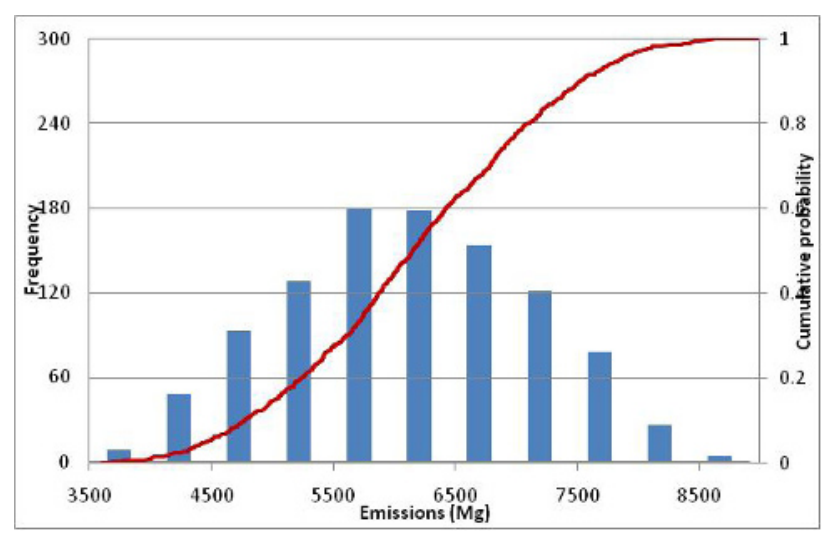

b)

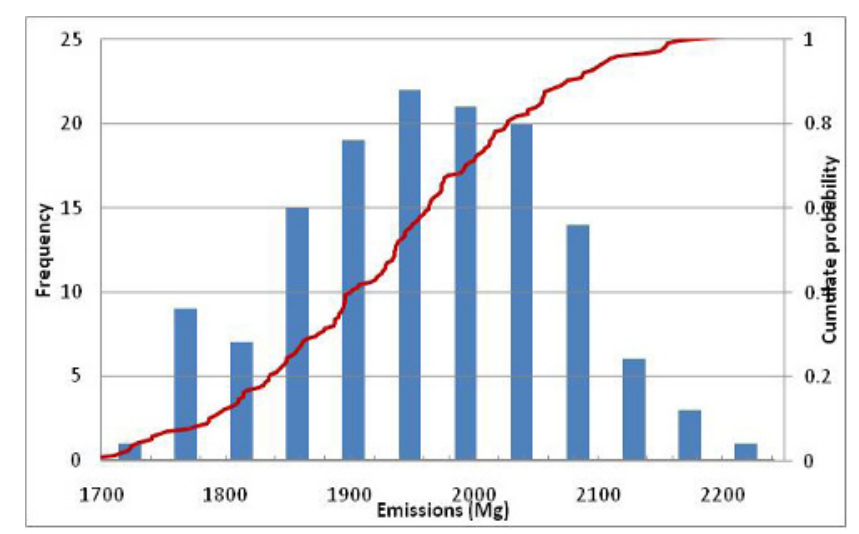

Fig. 1. Frequency and cumulative distribution curves of total simulated emissions from natural sources a). and anthropogenic sources b). Both figures are based on the $95 \%$ confidence interval, which led to 1019 and 138 iterations, respectively. 
associated with mercury emissionsby considering the following equation for cumulative probability:

$$
\operatorname{Pr}\left\{\left|\frac{1}{N} \sum_{N} \xi-\mu\right|<\frac{3 \sigma}{\sqrt{N}}\right\} \approx 0.997
$$

where $\mathrm{N}$ is the number of iterations, $\xi$ the variable, $\mu$ the average and the standard deviation.

We established upper and lower bounds for both natural and anthropogenic sources on the basis of several published papers and international reports (i.e., Sunderland and Mason 2007, Mason 2009, Pirrone et al. 2009, Pacyna et al., 2010; Pirrone et al., 2010).

For each category, we assumed a normal distribution. Therefore, the total emissions becomes anormally-distributed random variable with a value between the minimum and the maximum.

The total error given by $\varepsilon=\frac{3 \sigma}{\sqrt{\mathrm{N}}}$ was simulated at 5 , 10,20 and $30 \%$.

\section{Results and Discussion}

Table 1 reports the upper and lower boundaries, as well as the averages for each category, revealing a rather wide amplitude for natural sources ranging from $-141 \%$ to $+96 \%$; whereas, for anthropogenic sources, the range is between $-34 \%$ to $+25 \%$.

a)

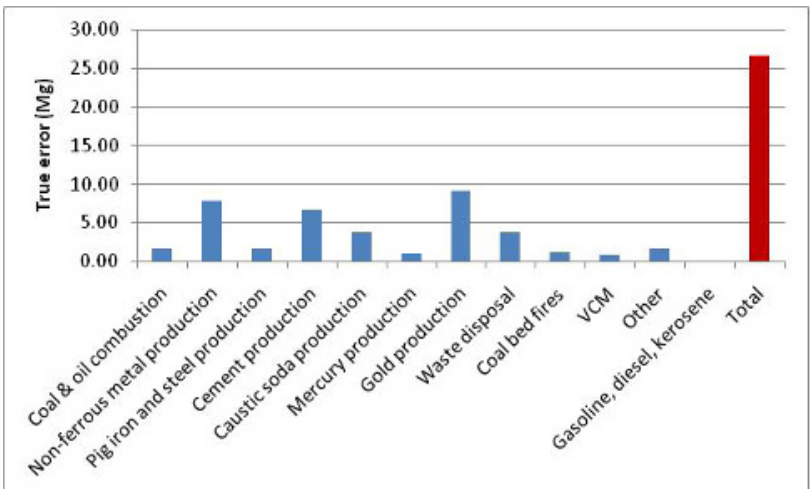

b)

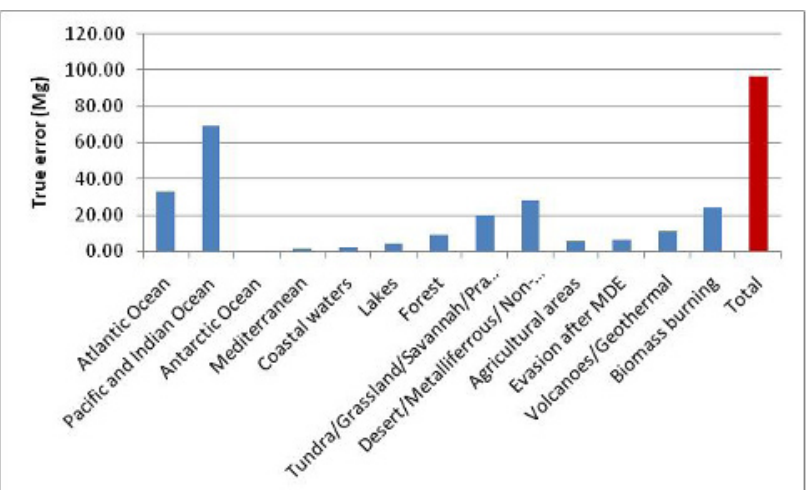

Fig. 2. True error estimated for each source category of natural a), and anthropogenic b) emission.
Calculated without uncertainty, the emission from total natural sources averaged $5206 \mathrm{Mg} \mathrm{y}^{-1}$; whereas it averaged $1930 \mathrm{Mg} \mathrm{y}^{-1}$ for anthropogenic sources.

Using the Monte Carlo approach with a 5\% confidence interval, emissions where 6165 and $1935 \mathrm{Mg}$ $\mathrm{y}^{-1}$ for natural and anthropogenic sources, respectively. The standard deviation was 1029 in the former, and 111 in the latter (Table 2). Results indicate a really close overlap with a Gaussian density distribution, despite the resampled mean reflecting a small bias in the resampling procedures (less than $3 \%$ in this case) (Figure 1). In addition to running a Monte Carlo simulation for total emissions, we also calculated each error source alone. With regard to anthropogenic emissions, we obtained a true error value that is low compared to the estimations by Streets et al. (2005), indicating that an overestimation of uncertainty exists prior to any consideration of statistical methods (Figure 2a). Non-ferrous smelters, cement, and gold industrial plants are associated with the largest uncertainty estimates. In addition, natural emissions have a high global uncertainty (Figure 2b). Emissions from oceans, as expected, have the largest uncertainty.

\section{Conclusion}

In the existing literature, estimations of both natural and anthropogenic emissions are associated with large uncertainties. Our simulations using the Monte Carlo technique demonstrated that, on the contrary, these uncertainties are overestimated. Though, it is important to note that this probabilistic approach does not consider the accuracy of the available input data, but is instead based on a range of values whose calculations cannot be analysed here.

For a more reliable calculation of the components of the overall uncertainty in computing mercury emissions into atmosphere, it is best to use a number of different techniques (e.g. the Ishikawa cause and effect diagram), so that one can obtain a qualitative analysis of all the factors involved.

As employed here, the Monte Carlo technique produces an estimate of overall uncertainty in calculating atmospheric mercury emissions, While its main components have been simplified, it continues to improve our assessment of mercury emission uncertainty.

\section{Acknowledgements}

The authors would like to thank for financial support provided by the GMOS Project (FP7-ENV-2010 No. 265113).

\section{References}

AMAP/UNEP (2008), Technical background report to the global atmospheric mercury assessment, $159 \mathrm{pp}$, Arctic Monitoring and Assessment Programme/UNEP Chemicals Branch, Geneva, 
Switzerland.

Buslenko NP, Golenko DI, Shreider YA, Sobol IM, Sragovich VG. The Monte Carlo method. Pergamon; 1966.

Friedli, H. R., et al. (2009a), Mercury emissions from global biomass burning: spatial and temporal distribution, in Mercury Fate and Transport in the Global Atmosphere: Emissions, Measurements, and Models, edited by N. Pirrone and R. P. Mason, 193-221 pp., Springer, New York.

Friedli, H. R., et al. (2009b), Initial estimates for mercury emissions to the atmosphere from global biomass burning, Environmental Science \& Technology, 43(10): 3507-3513

Hammersley, JM, Handscomb, DC, Monte-Carlo Methods. General Editors: MS Bartlett, FRS, DR Cox, 1979

Lindberg, S. E., et al. (2007), A synthesis of progress and uncertainties in attributing the sources of mercury in deposition, AMBIO: A Journal of the Human Environment, 36(1): 19-32.

Pacyna, E. G., et al. (2010), Global emission of mercury to the atmosphere from anthropogenic sources in 2005 and projections to 2020, Atmospheric Environment, 40(20): 2487-2499.

Pacyna, J. M., et al. (2003), Mapping 1995 global anthropogenic emissions of mercury, Atmospheric Environment, 37(S1): 109-117.

Pirrone, N., and R. P. Mason (Eds.) (2009), Mercury Fate and Transport in the Global Atmosphere: Emissions,
Measurements, and Models, 637 pp., Springer, New York

Pirrone, N., et al. (2010), Global mercury emissions to the atmosphere from anthropogenic and natural sources, Atmospheric Chemistry and Physics, 10(13): 5951-5964.

Streets, D. G., et al. (2003), An inventory of gaseous and primary aerosol emissions in Asia in the year 2000, Journal of Geophysical Research, 108(D21): $8809-8831$.

Streets, D. G., et al. (2009a), Mercury emissions from coal combustion in China, in Mercury Fate and Transport in the Global Atmosphere: Emissions, Measurements, and Models, edited by N. Pirrone and R. P. Mason, 51-65 pp., Springer, New York.

Streets, D. G., et al. (2009b), Projections of global mercury emissions in 2050, Environmental Science \& Technology, 43(8): 2983-2988.

Swain, E. B., et al. (2007), Socioeconomic consequences of mercury use and pollution, Ambio A Journal for the Human Environment, 36(1): 45-61.

$\mathrm{Wu}$, R., et al. (2009), Findings from quality assurance activities in the Integrated Atmospheric Deposition Network, Journal of Environmental Monitoring, 11: 277-296.

$\mathrm{Wu}, \mathrm{Y}$., et al. (2006), Mercury emissions from China: Current status and future trend, paper presented at Proceedings of the 2006 Air \& Waste Management Association 99th Annual Conference, New Orleans, LA. 